\title{
Prognostic value of multiple epithelial mesenchymal transition-associated proteins in intrahepatic cholangiocarcinoma
}

\author{
XIANGGUO TIAN $^{1}$, ZHIXIN CAO ${ }^{2}$, QIAN DING $^{1}$, ZHEN LI $^{1}$ and CHUNQING ZHANG ${ }^{1}$ \\ Departments of ${ }^{1}$ Gastroenterology and ${ }^{2}$ Pathology, Shandong Provincial Hospital \\ Affiliated to Shandong University, Jinan, Shandong 250021, P.R. China
}

Received March 31, 2018; Accepted April 5, 2019

DOI: $10.3892 / \mathrm{ol} .2019 .10522$

\begin{abstract}
The aim of the present study was to investigate the expression of epithelial mesenchymal transition (EMT)-associated proteins and their prognostic value in intrahepatic cholangiocarcinoma (ICC). The expression of six EMT-associated proteins, including E-cadherin, N-cadherin, Vimentin, Snail family transcriptional repressor 1 (Snail), Snail family transcriptional repressor 2 (Slug) and S100 calcium binding protein A4 (S100A4) was determined by immunohistochemistry in 109 patients with ICC who had received surgery. Survival analysis showed that patients with low E-cadherin expression $(\mathrm{P}<0.001)$ or high S100A4 $(\mathrm{P}<0.001)$ or Snail $(\mathrm{P}<0.001)$ expression had a reduced survival time. Based on the numbers of alterations in the expression of EMT-associated proteins as determined by immunohistochemical analysis, the patients were categorized as low (score, $0-3 ; n=75$ ) or high (score, $\geq 4 ; n=34$ ) EMT expression groups. The high EMT expression group was significantly associated with positive lymph node metastasis $(\mathrm{P}=0.023)$ and late Tumor-Node-Metastasis (TNM) stage $(\mathrm{P}<0.001)$. Furthermore, patients in the high EMT expression group had a significantly poorer overall survival time than those in the low EMT expression group $(\mathrm{P}<0.001)$. Multivariate analysis indicated that EMT status was a significant independent predictor for overall survival time $(\mathrm{P}=0.004)$, and was linked to surgical margin $(\mathrm{P}=0.013)$ and TNM stage $(\mathrm{P}<0.001)$. In conclusion, the reduced expression of E-cadherin and high expression of Snail and S100A4 were significantly associated with the poor survival of patients with ICC after surgery. The EMT protein
\end{abstract}

Correspondence to: Dr Chunqing Zhang, Department of Gastroenterology, Shandong Provincial Hospital Affiliated to Shandong University, 324 Jingwu Weiqi Road, Jinan, Shandong 250021, P.R. China

E-mail: chunqing1963@126.com

Abbreviations: ICC, intrahepatic cholangiocarcinoma; EMT, epithelial-mesenchymal transition

Key words: ICC, prognosis, EMT, immunohistochemistry, survival analysis expression status was associated with ICC progression, and may be considered as an independent prognostic indicator for patients with ICC.

\section{Introduction}

Intrahepatic cholangiocarcinoma (ICC) is the second most common primary liver cancer diagnosed worldwide (1-3). In the past decades, the incidence of ICC has been rising worldwide, including Europe, North America, Asia, Japan and Australia (4). In a 30-year period the incidence of ICC increased $165 \%$ in the United States to 0.95 cases per 100,000 (4). Despite the continuous development of therapeutic options, including surgery, chemotherapy and radiotherapy, the prognosis for ICC remains poor (5). The molecular mechanisms underlying the invasion and metastasis of ICC remain unclear. Identifying these mechanisms, and therefore, novel molecular biomarkers, is crucial for early disease detection, prognostic evaluation and the development novel treatment strategies for ICC.

The epithelial-mesenchymal transition (EMT), a series of events during which epithelial cells lose many of their epithelial characteristics to gain a mesenchymal phenotype, is a pivotal mechanism in tumor progression and metastasis $(6,7)$. The hallmark of EMT comprises the downregulation of epithelial molecules, such as E-cadherin, Keratin 19 and mucin-1, cell surface associated, and the upregulation of mesenchymal molecules, including Vimentin, S100 calcium binding protein A4 (S100A4), N-cadherin, fibronectin and $\beta$-catenin (7-9). A number of transcription factors, including Snail family transcriptional repressor 1 (Snail), Snail family transcriptional repressor 2 (Slug), Twist family BHLH transcription factor (Twist), Zinc finger E-box binding homeobox 1 (Zeb1) and Zeb2, are also known to serve a central role in the activation of EMT (8-10). This process has been associated with tumor invasion, metastasis and a poor prognosis in various types of gastrointestinal tumor, including esophageal, gastric, colorectal and hepatic carcinomas (11-14).

Numerous EMT-associated proteins have been suggested to be associated with tumor progression in ICC (15-19). However, to the best of our knowledge, no previous study has been performed to evaluate the EMT process in ICC through the measurement of a large number of EMT-associated markers.

In the present study, the association between the expression of six representative EMT-associated proteins, including 
E-cadherin, N-cadherin, Vimentin, Snail, Slug and S100A4, and survival in ICC was assessed. In addition, the clinicopathological significance and prognostic value of the expression profile of EMT-related proteins, based on the number of alterations in the expression of these proteins, were also investigated to evaluate the clinical significance of EMT-associated proteins in patients with ICC.

\section{Materials and methods}

Patients. A panel of 109 surgical ICC tissue specimens was obtained from patients undergoing curative resection at the Shandong Provincial Hospital Affiliated to Shandong University (Jinan, China) between January 2010 and December 2015. Clinicopathological parameters, including age, sex, tumor size, histological differentiation, surgical margin, lymph node metastasis and Tumor-Node-Metastasis (TNM) stage (20), were obtained by reviewing clinical and pathological records (Table I). The patients included 60 males and 49 females (mean, 57.4 years; range, 39-75 years); all patients were followed-up. The follow-up period ranged from 5-73 months (mean, 26.3 months). None of the patients received neoadjuvant chemotherapy, radiotherapy or immunotherapy prior to surgery. The tumor stage was diagnosed by two certified pathologists of Shandong Provincial Hospital Affiliated to Shandong University, according to the TNM classification defined by the Union for International Cancer Control (20). The study was approved by the Institutional Ethics Committee of Shandong Provincial Hospital Affiliated to Shandong University, and informed written consent was obtained from each patient.

Immunohistochemistry. Briefly, $4 \mu \mathrm{m}$ thick sections of the $4 \%$ formalin-fixed, paraffin-embedded surgical specimens were baked at $60^{\circ} \mathrm{C}$ for at least $2 \mathrm{~h}$, and then were dewaxed in xylene and rehydrated using a descending alcohol series $(100 \%$ for $5 \mathrm{~min}, 85 \%$ for $5 \mathrm{~min}, 75 \%$ for $5 \mathrm{~min}$, distilled water). They were placed in a glass container filled with $10 \mathrm{mmol} / 1$ citrate buffer ( $\mathrm{pH}$ 6.0) and heated in a microwave for $15 \mathrm{~min}$ for antigen retrieval. Endogenous peroxidase activity was blocked by incubation in $3 \% \mathrm{H}_{2} \mathrm{O}_{2}$ at room temperature for 15 min. Goat serum (1\%) (cat. no., AR1009; Wuhan Boster Biological Technology, Ltd.) was applied to sections to block nonspecific binding for $5 \mathrm{~min}$ at room temperature. Sections were then incubated overnight at $4^{\circ} \mathrm{C}$ with primary antibodies, including: Rabbit anti-E-cadherin (cat. no., ab40772; 1:200; Abcam), anti-N-cadherin (cat. no., ab76011; 1:200; Abcam), anti-Vimentin (cat. no., ab92547; 1:200; Abcam), anti-S100A4 (cat. no., ab124805; 1:200; Abcam), anti-Snail (cat. no., 13099-1-AP; 1:100; ProteinTech Group, Inc.) or anti-Slug (cat. no., 12129-1-AP; 1:100; ProteinTech Group, Inc.). The sections were then treated with HRP-labelled universal secondary antibody (cat. no., K5007; Dako) for $30 \mathrm{~min}$ at $37^{\circ} \mathrm{C}$. Slides were washed with PBS in triplicate and 3,3'-diaminobenzidine solution was added for 2-3 min at room temperature, which was incubated until the desired staining was achieved. Then the sections were counterstained with hematoxylin for 3-5 min at room temperature, and then dehydrated and mounted. The slides were observed using a light microscope (magnification, $\mathrm{x} 400$ ).
Evaluation of immunohistochemical staining. The degree of immunostaining of the sections was blindly evaluated semi-quantitatively by two pathologists of Shandong Provincial Hospital Affiliated to Shandong University, unaware of any clinical information. For each section, five high-power fields using light microscope (magnification, $\mathrm{x} 400$ ) were randomly selected. For the evaluation of E-cadherin expression, staining within the membrane was considered as positive immunostaining. For evaluation of $\mathrm{N}$-cadherin, Vimentin, Snail, Slug and S100A4 expression, staining in the cytoplasm and/or the nucleus was considered positive immunostaining. The expression of E-cadherin was considered low if the tumor cells exhibited weaker staining patterns than the normal epithelium, or when no staining was observed. The staining of $\mathrm{N}$-cadherin, Vimentin, Snail, Slug and S100A4 were evaluated on the basis of staining intensity and the proportion of positive cells. The tissue sections were scored based on the percentage of immunostained cells as follows: $0,<5 ; 1,5-25 ; 2,26-50$ and $3,>51 \%$. Sections were also scored on the basis of staining intensity: 0 , negative; 1 , weak; 2 , moderate and 3 , strong (21). A final score was obtained by multiplying the intensity and percentage scores. Tumors were divided into low (total score of 0-2) and high (a total score of >2) expression groups.

Statistical analysis. The associations between alterations in the expression of EMT proteins and clinicopathological variables were examined by a $\chi^{2}$ test. Survival curves were produced using the Kaplan-Meier method and compared with the log-rank test. Univariate and multivariate analyses were performed to identify independent prognostic factors using the Cox proportional hazards regression model. $\mathrm{P}<0.05$ was considered to indicate a statistically significant difference. All statistical analyses were performed using SPSS 17.0 software (SPSS Inc., Chicago, IL, USA).

\section{Results}

Expression of EMT-associated proteins in primary ICC. Fig. 1 shows representative images of immunohistochemical staining for the EMT-associated proteins in the tumor tissue samples. Low E-cadherin expression was observed in 63 $(57.8 \%)$ of the samples. Regarding the mesenchymal markers and transcription factors, 39 (35.8\%) of the samples exhibited high Vimentin, 42 (38.5\%) exhibited high S100A4 expression; 35 (32.1\%), 38 (34.9\%) and 27 (24.8\%) samples revealed upregulated N-cadherin, Snail and Slug protein expression, respectively.

Association between EMT-associated protein expression and patient survival time. The log-rank test was used to identify the differences in patient survival time with respect to the expression of the six EMT-associated proteins (Fig. 2). During the follow-up period, a total of 67 (61.5\%) of the patients succumbed to ICC. In terms of epithelial markers, the survival time for patients with tumors with low expression of E-cadherin was significantly lower than the rate for patients with high expression of E-cadherin $(\mathrm{P}<0.001)$. In terms of mesenchymal markers and transcription factors, increased expression of S100A4 $(\mathrm{P}<0.001)$ and Snail $(\mathrm{P}<0.001)$ was associated with a lower survival rate compared with the low 
Table I. Association between EMT status and clinicopathological features in patients with intrahepatic cholangiocarcinoma.

\begin{tabular}{|c|c|c|c|c|}
\hline Variables & $\begin{array}{l}\text { Cases } \\
(n=109)\end{array}$ & $\begin{array}{c}\text { Group } 1 \\
\text { (low EMT expression, } \mathrm{n}=75 \text { ) }\end{array}$ & $\begin{array}{c}\text { Group } 2 \\
\text { (high EMT expression , } \mathrm{n}=34 \text { ) }\end{array}$ & P-value \\
\hline \multicolumn{5}{|l|}{ Sex } \\
\hline Male & 60 & 41 & 19 & \\
\hline Female & 49 & 34 & 15 & 0.906 \\
\hline \multicolumn{5}{|l|}{ Age (years) } \\
\hline$\leq 60$ & 56 & 38 & 18 & \\
\hline$>60$ & 53 & 37 & 16 & 0.826 \\
\hline \multicolumn{5}{|l|}{ Tumor size (cm) } \\
\hline$\leq 4$ & 47 & 33 & 14 & \\
\hline$>4$ & 62 & 42 & 20 & 0.783 \\
\hline \multicolumn{5}{|l|}{ Macroscopic types } \\
\hline Mass-forming type & 74 & 52 & 22 & \\
\hline Non-mass-forming type & 35 & 23 & 12 & 0.632 \\
\hline \multicolumn{5}{|l|}{ Histological differentiation } \\
\hline Well/moderate & 69 & 49 & 20 & \\
\hline Poor/undifferentiated & 40 & 26 & 14 & 0.514 \\
\hline \multicolumn{5}{|l|}{ Surgical margin } \\
\hline Positive & 28 & 17 & 11 & \\
\hline Negative & 81 & 58 & 23 & 0.284 \\
\hline \multicolumn{5}{|l|}{ Vascular invasion } \\
\hline Positive & 38 & 25 & 13 & \\
\hline Negative & 71 & 50 & 21 & 0.619 \\
\hline \multicolumn{5}{|l|}{ Lymph node metastasis } \\
\hline Positive & 32 & 17 & 15 & \\
\hline Negative & 77 & 58 & 19 & $0.023^{\mathrm{a}}$ \\
\hline \multicolumn{5}{|l|}{ T stage } \\
\hline $\mathrm{T} 1+\mathrm{T} 2$ & 66 & 45 & 21 & \\
\hline $\mathrm{T} 3+\mathrm{T} 4$ & 43 & 30 & 13 & 0.861 \\
\hline \multicolumn{5}{|l|}{ TNM stage (17) } \\
\hline $\mathrm{I}+\mathrm{II}$ & 61 & 52 & 9 & \\
\hline III+IV & 48 & 23 & 25 & $<0.001^{\mathrm{a}}$ \\
\hline
\end{tabular}

${ }^{\mathrm{a}} \mathrm{P}<0.05$ low EMT expression vs. high EMT expression. EMT, epithelial mesenchymal transition; TNM, Tumor-Node-Metastasis.

expression group. However, there were no significant differences in survival time between the high and low expression groups with respect to $\mathrm{N}$-cadherin $(\mathrm{P}=0.066)$, Slug $(\mathrm{P}=0.956)$ and Vimentin $(\mathrm{P}=0.430)$ expression.

Association between EMT status and the survival of patients. According to the number of downregulated epithelial proteins and upregulated mesenchymal and transcription proteins in each patient, the EMT status of patients was categorized into 2 groups: i) Group 1: (low EMT expression, score, 0-3; $\mathrm{n}=75$ ), with the alteration number of $\leq 3$; ii) Group 2: (high EMT expression, score, $\geq 4 ; n=34$ ), with the alteration number of $\geq 4$ ).

The characteristics of the patients from each group are outlined in Table I. $\chi^{2}$ analysis showed that patients with high EMT expression exhibited a significantly greater likelihood of lymph node metastasis $(\mathrm{P}=0.023)$ and a higher TNM stage $(\mathrm{P}<0.001)$.

The cumulative survival rates at 1, 2 and 5 years were 61.8, 25.2 and 3.2\%, respectively, in the high EMT expression group, whereas they were 88.0, 74.1 and 31.5\% in the low EMT expression group. The survival rate for patients with high EMT expression was significantly lower than that in patients with low EMT expression $(\mathrm{P}<0.001$; Fig. 3).

Univariate and multivariate analysis were performed to identify independent prognostic factors by using the Cox proportional hazards regression model. Univariate analysis demonstrated that the significant prognostic factors included EMT status $(\mathrm{P}<0.001)$, lymph node metastasis $(\mathrm{P}=0.025)$, vascular invasion $(\mathrm{P}=0.027)$, surgical margin $(\mathrm{P}<0.001)$ and TNM stage $(\mathrm{P}<0.001)$. The above five significant factors were analyzed by multivariate analysis and it was indicated 
A
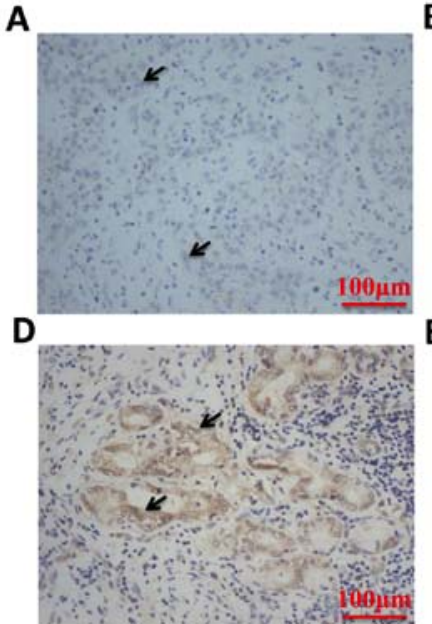

B
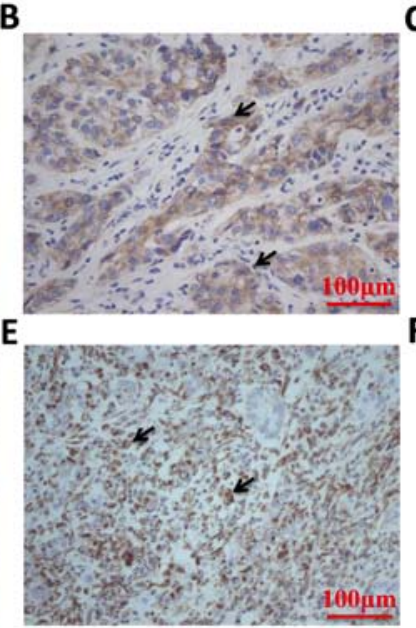

C

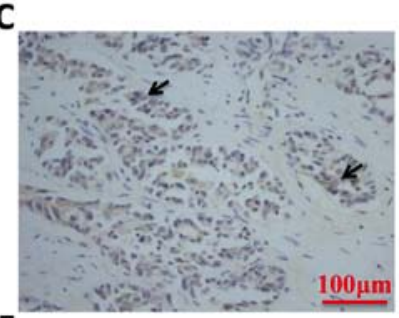

$\mathbf{F}$

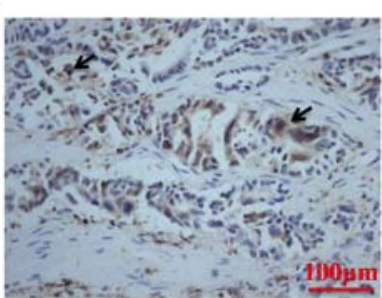

Figure 1. Representative immunohistochemical staining for the EMT-associated proteins in intrahepatic cholangiocarcinoma. The low expression of (A) E-cadherin, and high expression of (B) N-cadherin, (C) Snail, (D) Slug, (E) Vimentin and (F) S100A4 were observed in tumor tissues (the black arrows, magnification, x400). Snail, Snail family transcriptional repressor 1; Slug, Snail family transcriptional repressor 2; S100A4, S100 calcium binding protein A4; EMT, epithelial-mesenchymal transition.
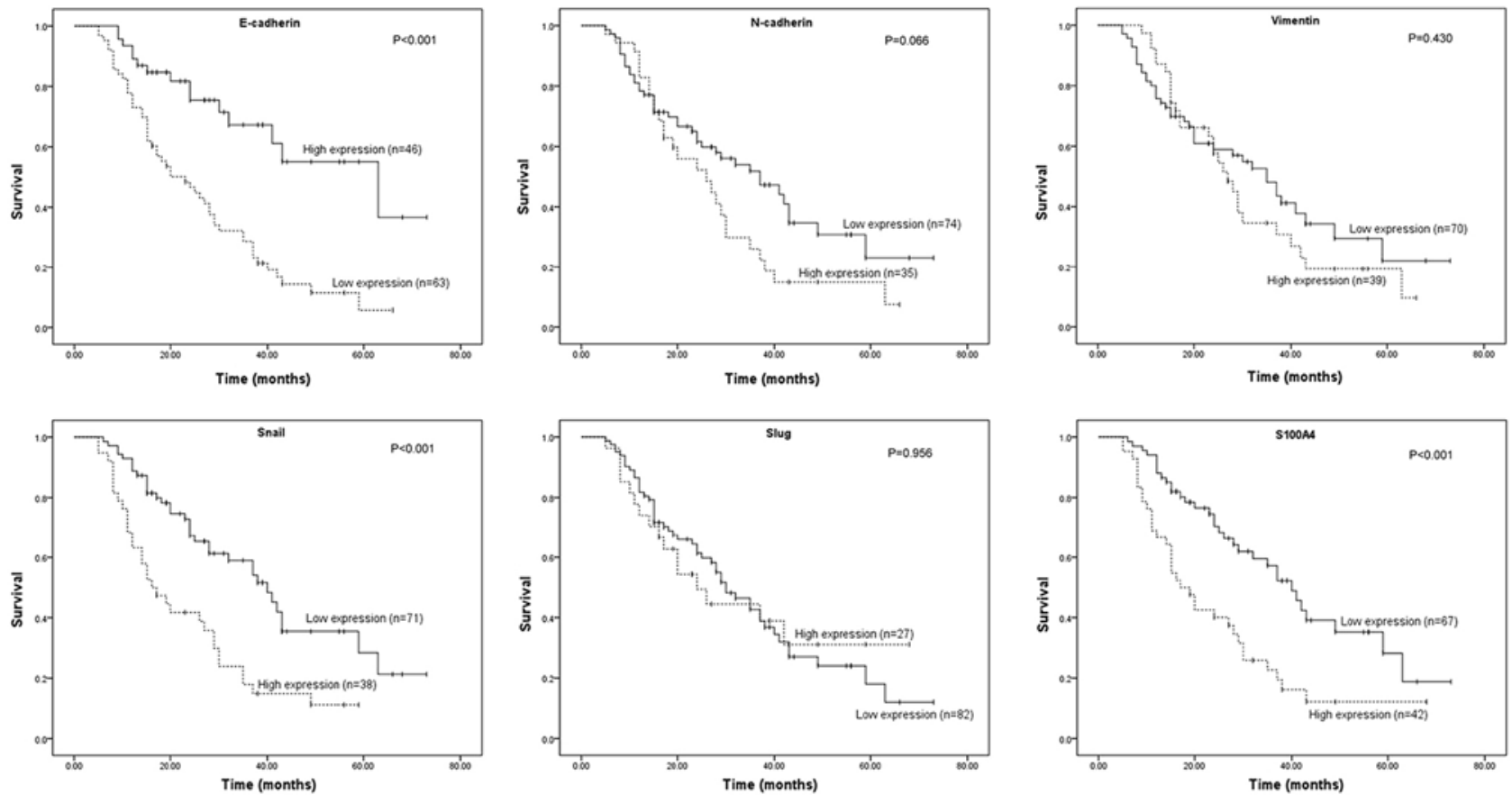

Figure 2. Survival curves using the Kaplan-Meier method for expression of the six EMT-associated proteins in patients with intrahepatic cholangiocarcinoma. Snail, Snail family transcriptional repressor 1; Slug, Snail family transcriptional repressor 2; S100A4, S100 calcium binding protein A4; EMT, epithelial-mesenchymal transition.

that EMT status $(\mathrm{P}=0.004)$, surgical margin $(\mathrm{P}=0.013)$ and TNM stage $(\mathrm{P}<0.001)$ were independent prognostic factors for overall survival rate (Table II).

\section{Discussion}

EMT serves a crucial role in cancer invasion, metastasis and progression (6,7). Although numerous EMT-associated markers have been reported to be effective prognostic factors for patients who have undergone curative resection in many types of digestive tumours, including esophageal, gastric, colorectal and hepatic carcinomas (11-14), few studies have focused on the expression and prognostic value of EMT markers in ICC (15-19). Therefore, further investigation into the prognostic value and clinical significance of EMT in ICC is required. In the present study, the expression of six EMT-associated proteins was analyzed in a relatively large cohort of patients with ICC, in addition to their association with overall survival rate. Furthermore, the association of EMT status, based on the number of expression changes to EMT markers, with clinicopathological factors and prognosis was also investigated to determine the clinical significance of EMT in ICC. To the best of our knowledge, this is the first study to evaluate the clinical role of EMT, 
Table II. Univariate and multivariate analysis of prognostic factors for overall survival rate.

\begin{tabular}{|c|c|c|c|c|c|c|}
\hline \multirow[b]{2}{*}{ Variables } & \multicolumn{3}{|c|}{ Univariate analysis } & \multicolumn{3}{|c|}{ Multivariate analysis } \\
\hline & $\mathrm{RR}$ & $95 \% \mathrm{CI}$ & P-value & $\mathrm{RR}$ & $95 \% \mathrm{CI}$ & P-value \\
\hline Sex (male vs. female) & 1.079 & $0.666-1.749$ & 0.757 & - & - & - \\
\hline Age $(\leq 60$ vs. $>60)$ & 0.940 & $0.582-1.519$ & 0.800 & - & - & - \\
\hline Tumor size $(\leq 4 \mathrm{vs.}>4 \mathrm{~cm})$ & 1.221 & $0.748-1.995$ & 0.425 & - & - & - \\
\hline Macroscopic types (mass-forming vs. non-mass-forming) & 1.543 & $0.935-2.546$ & 0.090 & - & - & - \\
\hline $\begin{array}{l}\text { Histological differentiation } \\
\text { (well/moderate vs. poor/undifferentiated) }\end{array}$ & 0.867 & $0.519-1.448$ & 0.586 & - & - & - \\
\hline Surgical margin (positive vs. negative) & 3.876 & $2.196-6.841$ & $<0.001^{\mathrm{a}}$ & 2.218 & $1.185-4.152$ & $0.013^{\mathrm{a}}$ \\
\hline Vascular invasion (positive vs. negative) & 1.741 & $1.065-2.844$ & $0.027^{\mathrm{a}}$ & 1.296 & $0.739-2.275$ & 0.365 \\
\hline Lymph node metastasis (positive vs. negative) & 1.813 & $1.077-3.052$ & $0.025^{\mathrm{a}}$ & 1.398 & $0.806-2.426$ & 0.233 \\
\hline T stage (T1+T2 vs. T3+T4) & 1.003 & $0.611-1.647$ & 0.991 & - & - & - \\
\hline TNM stage (17) (I+II vs. III+IV) & 7.714 & $4.293-13.859$ & $<0.001^{\mathrm{a}}$ & 4.919 & 2.585-9.359 & $<0.001^{\mathrm{a}}$ \\
\hline EMT status (high vs. low) & 4.180 & $2.529-6.908$ & $<0.001^{\mathrm{a}}$ & 2.305 & $1.311-4.050$ & $0.004^{\mathrm{a}}$ \\
\hline
\end{tabular}

${ }^{\mathrm{a}}<0$.05. CI, confidence interval; RR, relative risk; EMT, epithelial-mesenchymal transition; TNM, Tumor-Node-Metastasis.

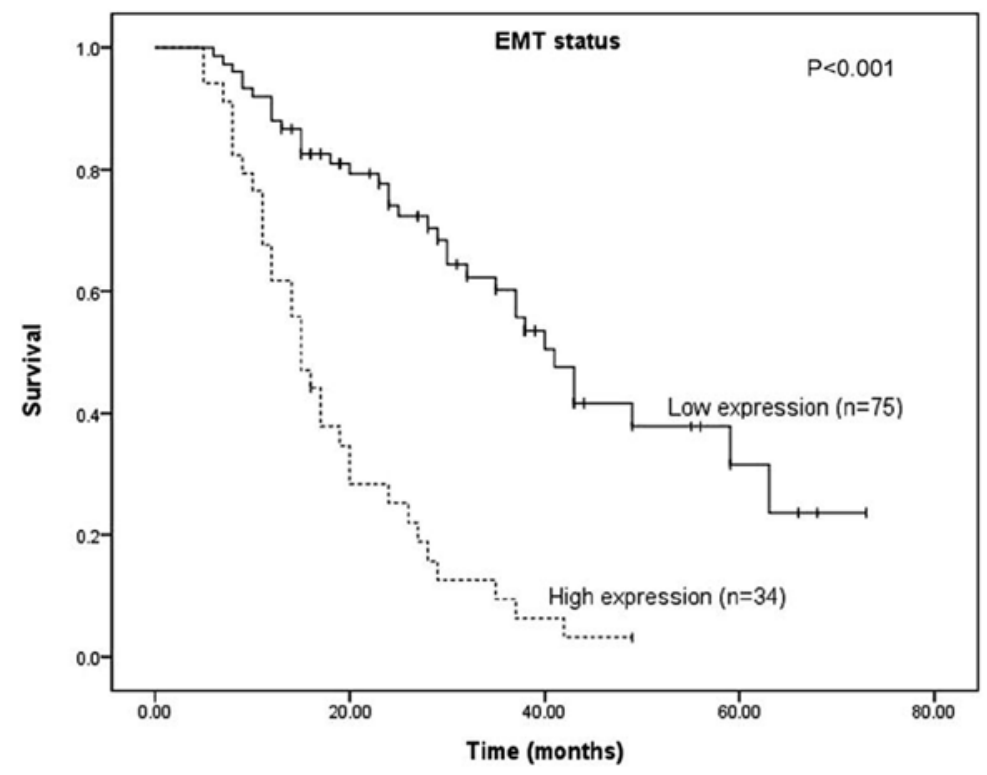

Figure 3. Survival curves using the Kaplan-Meier method for the EMT expression status in patients with intrahepatic cholangiocarcinoma. EMT, epithelialmesenchymal transition.

taking into consideration the expression of several EMT proteins in ICC.

E-cadherin is expressed in the membranes of epithelial cells and serves a vital role in cell adhesion and movement (22). The loss of E-cadherin expression promotes the migration and invasion of tumor cells, and is a critical step of EMT in the development of malignant carcinomas (23). A number of transcription factors, including Snail, Slug, Twist, Zeb1 and Zeb2, induce EMT by downregulating E-cadherin, and upregulating mesenchymal factors, such as N-cadherin, Vimentin and S100A4, through a number of different signalling cascades, such as the signal transducer and activator of transcription 3, mitogen-activated protein kinase and Wnt pathways $(8-10,24)$.
In the present study, the downregulation of an epithelial marker (E-cadherin) and the upregulation of mesenchymal markers (Vimentin, N-cadherin and S100A4) were detected. The EMT transcription factors Snail and Slug were also highly expressed in ICC tissue samples. These representative characteristic changes confirmed the occurrence of EMT in ICC tissue. Furthermore, survival analysis showed that reductions in E-cadherin expression, and increased expression of S100A4 and Snail was associated with significantly shorter overall survival time.

S100A4 is a typical fibroblast marker of EMT; furthermore, it is involved in the regulation of various biological processes, including cell proliferation, extracellular matrix remodelling, 
cell motility, cell detachment and angiogenesis (25). S100A4 expression has been reported to be significantly associated with cancer aggressiveness and a worse prognosis for patients with several types of cancer, such as pancreatic, bladder, gallbladder, breast, ovarian, colorectal and gastric cancer, and non-small cell lung carcinoma, and may be a useful marker of metastatic potential with prognostic significance (26). S100A4 expression has also been reported to increase the invasiveness and metastasis of cholangiocarcinoma in vitro and in vivo (27). In our previous study, the high expression of S100A4 was identified as an independent predictor for reduced overall survival time in ICC (21). The outcomes in the present larger scale study were consistent with the aforementioned studies.

Among the EMT transcription factors, the Snail family, including Snail and Slug, are the most extensively studied (28-31). Slug and Snail have been identified to serve key roles in the development of several types of carcinoma, including renal, breast, prostate and ovarian carcinomas (28-31). The Snail family facilitates the metastatic potential of tumors by promoting cell migration, inhibiting cell-cell adhesion and enhancing tumor invasiveness (32). The overexpression of Snail potently inhibits the expression of E-cadherin and induces EMT $(33,34)$. The inhibition of Slug expression by RNA interference is associated with upregulated E-cadherin expression and decreased cell invasion in vitro (35). In patients with ICC or hilar cholangiocarcinoma, high expression of Snail was reported to be associated with aggressive tumor characteristics and poor prognosis $(16,32)$. In ICC, the expression of Slug has been associated with lymph node invasion, lymphovascular invasion and distant metastasis, as well as acting as an independent indicator of poor prognosis (36). In the present study, the increased expression of Snail was associated with reduced overall survival for patients with ICC following surgical resection. However, we reported that upregulated Slug did not predict the unfavorable survival outcomes for patients with ICC.

Other EMT-associated proteins, such as $\beta$-catenin, $\mathrm{N}$-cadherin and Slug, have also previously been identified as reliable prognostic indicators and indicators for the likelihood of tumor invasion in many types of cancer, including ICC (15). However, only the E-cadherin, S100A4 and Snail expression levels were observed to be associated with poor survival in the present study. The differences in sample size, antibodies used, patient characteristics, follow-up periods and immunohistochemistry cut-off values could account for the differing results (17). The combined detection of EMT proteins could decrease the likelihood of bias. In addition, EMT proteins may interact with each other during cancer progression (19). The detection of the co-expression of EMT proteins would therefore be expected to have greater prognostic value than any single EMT protein. Therefore, in the present study, the association between the expression of a combination of EMT-related proteins with the clinicopathological features and prognosis of patients with ICC was determined. The frequency of EMT proteins dysregulation was used to reflect the EMT status in each tumor sample. Patients with a higher number of EMT protein alterations were more likely to exhibit lymph node metastasis and a higher TNM stage, as well as poorer overall prognosis. The results collectively demonstrated that EMT is a key step in the progression of ICC.
In conclusion, the reduced expression of E-cadherin, and the increased expression of Snail and S100A4 were significantly associated with reduced overall survival time for patients with ICC after curative resection. The EMT status, based on the number of alterations in the expression of EMT-related proteins, was associated with ICC progression, and may serve as an independent prognostic indicator for ICC. Further investigations regarding the upstream or downstream factors of EMT in different mechanisms could provide the basis for the identification of diagnostic markers and potential therapeutic targets for ICC.

\section{Acknowledgements}

The authors would like to thank Dr Edward C. Mignot (Shandong University) for the linguistic advice.

\section{Funding}

This study was supported by Shandong Provincial Key Research and Development Program (grant no. 2017GSF218026) and Shandong Provincial Natural Science Foundation (grant no. ZR2017PH001).

\section{Availability of data and materials}

The datasets used and/or analyzed during the current study are available from the corresponding author on reasonable request.

\section{Authors' contributions}

$\mathrm{XT}$ and $\mathrm{CZ}$ were responsible for study concept and design. XT, ZC, QD and ZL performed the experiments. QD and ZL analysed the data. XT and $\mathrm{CZ}$ wrote the present manuscript. All authors read and approved the final manuscript.

\section{Ethics approval and consent to participate}

The study was approved by the Institutional Ethics Committee (Shandong Provincial Hospital Affiliated to Shandong University), and informed written consent was obtained from each patient.

\section{Patient consent for publication}

Written informed consent was obtained from each patient to publish the present study.

\section{Competing interests}

The authors declare that they have no competing interests.

\section{References}

1. Razumilava N and Gores GJ: Cholangiocarcinoma. Lancet 383: 2168-2179, 2014

2. Bridgewater J, Galle PR, Khan SA, Llovet JM, Park JW, Patel T, Pawlik TM and Gores GJ: Guidelines for the diagnosis and management of intrahepatic cholangiocarcinoma. J Hepatol 60: 1268-1289, 2014.

3. Gupta A and Dixon E: Epidemiology and risk factors: Intrahepatic cholangiocarcinoma. Hepatobiliary Surg Nutr 6: 101-104, 2017. 
4. Zhang H, Shen F, Han J, Shen YN, Xie GQ, Wu MC and Yang T: Epidemiology and surgical management of intrahepatic cholangiocarcinoma. Hepat Oncol 3: 83-91, 2016.

5. Shaib YH, Davila JA, McGlynn K and El-Serag HB: Rising incidence of intrahepatic cholangiocarcinoma in the United States: A true increase? J Hepatol 40: 472-477, 2004.

6. Iwatsuki M, Mimori K, Yokobori T, Ishi H, Beppu T, Nakamori S, Baba $\mathrm{H}$ and Mori M: Epithelial-mesenchymal transition in cancer development and its clinical significance. Cancer Sci 101: 293-299, 2010 .

7. Thiery JP, Acloque H, Huang RY and Nieto MA: Epithelialmesenchymal transitions in development and disease. Cell 139: 871-890, 2009.

8. Kalluri R and Weinberg RA: The basics of epithelial-mesenchymal transition. J Clin Invest 119: 1420-1428, 2009.

9. Zeisberg M and Neilson EG: Biomarkers for epithelial-mesenchymal transitions. J Clin Invest 119: 1429-1437, 2009.

10. Tania M, Khan MA and Fu J: Epithelial to mesenchymal transition inducing transcription factors and metastatic cancer. Tumour Biol 35: 7335-7342, 2014

11. Wen J, Luo KJ, Liu QW, Wang G, Zhang MF, Xie XY, Yang H, $\mathrm{Fu} \mathrm{JH}$ and $\mathrm{Hu}$ Y: The epithelial-mesenchymal transition phenotype of metastatic lymph nodes impacts the prognosis of esophageal squamous cell carcinoma patients. Oncotarget 7 : 37581-37588, 2016.

12. Kim MA, Lee HS, Lee HE, Kim JH, Yang HK and Kim WH: Prognostic importance of epithelial-mesenchymal transitionrelated protein expression in gastric carcinoma. Histopathology 54: 442-451, 2009.

13. Cao H, Xu E, Liu H, Wan L and Lai M: Epithelial-mesenchymal transition in colorectal cancer metastasis: A system review. Pathol Res Pract 211: 557-569, 2015.

14. Giannelli G, Koudelkova P, Dituri F and Mikulits W: Role of epithelial to mesenchymal transition in hepatocellular carcinoma. J Hepatol 65: 798-808, 2016.

15. Vaquero J, Guedj N, Clapéron A, Nguyen Ho-Bouldoires TH, Paradis V and Fouassier L: Epithelial-mesenchymal transition in cholangiocarcinoma: From clinical evidence to regulatory networks. J Hepatol 66: 424-441, 2017.

16. Huang XY, Zhang C, Cai JB, Shi GM, Ke AW, Dong ZR, Zhang PF, Fan J, Peng BG and Zhou J: Comprehensive multiple molecular profile of epithelial mesenchymal transition in intrahepatic cholangiocarcinoma patients. PLoS One 9: e96860, 2014

17. Nitta T, Mitsuhashi T, Hatanaka Y, Miyamoto M, Oba K, Tsuchikawa T, Suzuki Y, Hatanaka KC, Hirano S and Matsuno Y: Prognostic significance of epithelial-mesenchymal transition-related markers in extrahepatic cholangiocarcinoma: Comprehensive immunohistochemical study using a tissue microarray. Br J Cancer 111: 1363-1372, 2014.

18. Yao X, Wang X, Wang Z, Dai L, Zhang G, Yan Q and Zhou W: Clinicopathological and prognostic significance of epithelial mesenchymal transition-related protein expression in intrahepatic cholangiocarcinoma. Onco Targets Ther 5: 255-261, 2012.

19. Ryu HS, Chung JH, Lee K, Shin E, Jing J, Choe G, Kim H, Xu X, Lee HE,KimDG, et al: Overexpression of epithelial-mesenchymal transition-related markers according to cell dedifferentiation: Clinical implications as an independent predictor of poor prognosis in cholangiocarcinoma. Hum Pathol 43: 2360-2370, 2012.

20. Sobin LH, Gospodarowicz MK and Wittekind $\mathrm{CH}$ : TNM Classification of Malignant Tumours. 7th edition. Wiley-Blackwell, Oxford, pp122-128, 2009.
21. Tian XG, Wang QZ, Li Y, Hu JH, Wu L, Ding Q and Zhang C: The expression of S100A4 protein in human intrahepatic cholangiocarcinoma: Clinicopathologic significance and prognostic value. Pathol Oncol Res 21: 195-201, 2015.

22. Shiozaki H, Tahara H, Oka H, Miyata M, Kobayashi K, Tamura S, Iihara K, Doki Y, Hirano S, Takeichi M, et al: Expression of immunoreactive E-cadherin adhesion molecules in human cancers. Am J Pathol 139: 17-23, 1991.

23. Huber MA, Kraut $\mathrm{N}$ and Beug $\mathrm{H}$ : Molecular requirements for epithelial-mesenchymal transition during tumor progression. Curr Opin Cell Biol 17: 548-558, 2005.

24. Hugo H, Ackland ML, Blick T, Lawrence MG, Clements JA, Williams ED and Thompson EW: Epithelial-mesenchymal and mesenchymal-epithelial transitions in carcinoma progression. J Cell Physiol 213: 374-383, 2007.

25. Mazzucchelli L: Protein S100A4: Too long overlooked by pathologists? Am J Pathol 160: 7-13, 2002.

26. Boye K and Maelandsmo GM: S100A4 and metastasis: A small actor playing many roles. Am J Pathol 176: 528-535, 2010.

27. Fabris L, Cadamuro M, Moserle L, Dziura J, Cong X, Sambado L, Nardo G, Sonzogni A, Colledan M, Furlanetto A, et al: Nuclear expression of S100A4 calcium-binding protein increases cholangiocarcinoma invasiveness and metastasization. Hepatology 54: 890-899, 2011.

28. Mikami S, Katsube K, Oya M, Ishida M, Kosaka T, Mizuno R, Mukai M and Okada Y: Expression of Snail and Slug in renal cell carcinoma: E-cadherin repressor Snail is associated with cancer invasion and prognosis. Lab Invest 91: 1443-1458, 2011.

29. Kurrey NK, K A and Bapat SA: Snail and Slug are major determinants of ovarian cancer invasiveness at the transcription level. Gynecol Oncol 97: 155-165, 2005.

30. Emadi Baygi M, Soheili ZS, Schmitz I, Sameie S and Schulz WA: Snail regulates cell survival and inhibits cellular senescence in human metastatic prostate cancer cell lines. Cell Biol Toxicol 26: 553-567, 2010.

31. Blechschmidt K, Sassen S, Schmalfeldt B, Schuster T, Höfler H and Becker KF: The E-cadherin repressor Snail is associated with lower overall survival of ovarian cancer patients. Br J Cancer 98: 489-495, 2008

32. Kong D, Liang J, Li R, Liu S, Wang J, Zhang K and Chen D: Prognostic significance of snail expression in hilar cholangiocarcinoma. Braz J Med Biol Res 45: 617-624, 2012.

33. Poser I, Dominguez D, de Herreros AG, Varnai A, Buettner R and Bosserhoff AK: Loss of E-cadherin expression in melanoma cells involves up-regulation of the transcriptional repressor Snail. J Biol Chem 276: 24661-24666, 2001.

34. Cano A, Perez-Moreno MA, Rodrigo I, Locascio A, Blanco MJ, del Barrio MG, Portillo F and Nieto MA: The transcription factor snail controls epithelial-mesenchymal transitions by repressing E-cadherin expression. Nat Cell Biol 2: 76-83, 2000.

35. Zhang KJ, Wang DS, Zhang SY, Jiao XL, Li CW, Wang XS, Yu QC and Cui HN: The E-cadherin repressor slug and progression of human extrahepatic hilar cholangiocarcinoma. J Exp Clin Cancer Res 29: 88, 2010.

36. Zhang KJ, Zhang BY, Zhang KP, Tang LM, Liu SS, Zhu DM and Zhang DL: Clinicopathologic significance of slug expression in human intrahepatic cholangiocarcinoma. World J Gastroenterol 16: 2554-2557, 2010 